\title{
Physical Activation of Elderly and the Decrease of Falling Risk
}

\author{
Martha Ornelas, Verónica Benavides, Juan F. Aguirre, Gabriel Gastélum*, \\ Judith M. Rodríguez-Villalobos
}

Faculty of Physical Culture Sciences, Autonomous University of Chihuahua, Chihuahua, México

Email: ${ }^{*}$ gastelum@uach.mx

Received 22 March 2014; revised 26 April 2014; accepted 4 May 2014

Copyright (C) 2014 by authors and Scientific Research Publishing Inc.

This work is licensed under the Creative Commons Attribution International License (CC BY). http://creativecommons.org/licenses/by/4.0/

c) (7) Open Access

\begin{abstract}
A Physical Activation Program was designed and implemented with a particular emphasis in recovering of motor independence, and in an indirect manner; the increase of activities was carried out in a social context in such a way that it allowed isolated elderly to develop their ability to perform daily activities diminishing the burden on their caregivers. 30 people were randomly selected: 15 subjects in the experimental group and 15 in the control group; 7 women and 8 men each group. Subjects aged between 60 - 84 years with a mean age of 78 years and a standard deviation of 6.5 were applied in a three-month Physical Activation Program with a 45-min daily sessions. Results obtained showed that physical activity in elderly, systematically improved their amplitude and joint mobility which impact directly and indirectly their quality of life, reducing their risk of falling.
\end{abstract}

\section{Keywords}

Physical Activation, Older Adult, Risk of Falling, Joint Mobility

\section{Introduction}

Since birth and subsequently in every cycle of life, humans have been adapting harmoniously in every stage of their lives whether it is childhood, adolescence, adulthood or elderly. This last stage seen as the main objective for this study represents physical, psychological and social changes in the human being.

Aging is the physiological process that begins with the conception and causes peculiar changes for a human throughout the life cycle. In the last years of life, these changes are the result of limitation in the adaptability of the organism in relation to the environment. The rhythms that these changes produce in the different organs of an individual or individuals are not the same [1].

"Corresponding author. 
The morphological changes that occur during aging will contribute to grand extent to the way that the subject perceives a greater or lower degree about the Self as an older adult. However, it has been shown that the environmental and social changes provide a higher pressure to make the elderly patient adopt and assume the old adult role [2].

Current statistics indicate and alarm us giving the rapid growth of older adult population, as a general tendency worldwide. In more specific data for our state of Chihuahua, México, the National Institute of Statistics, Geography and Informatics [3] indicated that $12.5 \%$ of the general population are elderly and it is estimated that by 2025 this number will increase to a quarter of the total population. This information takes to an expectation of the needs for health and social services as well as human development that will be demanded for this sector of the population, which is rapidly increasing.

At present in the state of Chihuahua, Mexico, older adults have the option of choosing permanent residence commonly called nursing homes; these institutions receive the elderly for care. Most of these institutions do not have a systematic geriatric assessment of their residents. The Comprehensive Geriatric Assessment (CGA) is a multidimensional, interdisciplinary diagnostic process designed to identify and quantify the physical, functional, psychological and social problems presented in the elderly, in order to develop a treatment plan and a follow-up of these problems as well as an optimal use of these resources [4].

Nursing homes of Chihuahua State lacked physical activation programs maintaining or improving physical, psychological, social and functional conditions of their residents. The World Health Organization (WHO) reported in 2002 that World Health estimates that sedentary lifestyles are one of the 10 main causes of death and disability in the world [5].

Manifestations of aging are modifiable, and clearly show exercise as a palliative. For example: against physical mismatch, physical activity; against the lack of cardiac reserve, aerobic exercise; against the lack of flexibility, stretching, and so many more possibilities of prevention and compensation. Staying active can help the elderly to: preserve and maintain the strength to remain independent, have more energy to do the things they want to do, improve balance, prevent or delay some diseases like heart disease, diabetes and cancer, improve their mood and decrease a status of depression. There is no need to buy special clothes or belong to a gym to be more active. Physical activity can and should be part of their daily lives [6] [7].

The response to an adequate physical activity delays the involution of skeletal muscle, provides joint activity preventing osteoporosis and bone fractures. It also delays cardiovascular involution preventing arteriosclerosis, respiratory and endocrine involution, creating a greater resistance and/or adaptation to stress [8].

The International Federation of Physical Education (IFPE) [9] in its Worldwide 2000 Physical Education concludes: "Physical Education needs to exert the function of Education for health so that it can act preventively against obesity-related diseases, heart disease, hypertension, some forms of cancer and depression, contributing to their overall quality of life. It should develop habits to practice regular physical activity".

Despite the multiple health benefits from physical exercise, the prevalence of sedentary lifestyles is increasing to alarming levels. Given this prevalence, all health professionals are challenged to promote physical activity and to educate the people about health benefits; and what they would receive through an active lifestyle. In this effort to change the behavior of the population, the analysis of attitudes and the study of the stages of change, a person goes to acquire the habit of a stable and balanced physical lifestyle [5].

Thirty-minute moderate intensity exercise every day or almost every day in a week provides important health benefits. This modest amount of physical activity, being frequent, can reduce or eliminate the risk of cardiovascular disease, diabetes mellitus type 2, osteoporosis, colon and breast cancer. Moderate but regular physical activity (climbing stairs, walking fast and cycling as part of a daily routine) can reduce stress, relieve depression and anxiety, enhance self-esteem and improve mental clarity [10] [11].

The benefit is not limited to activity maintaining older adults active and independent; this is, keeping these people active and surprised by the new physical and mental possibilities presented to them. Physical activity is a factor of fulfillment, quality of life and joy of living according to the personality of each person, giving them a healthier look and a fit body. It enables them to preserve more, vital and physical strength, as well as helping them to maintain and recover physical and mental balance. There is no guarantee that physical exercise gives more years to their life, but it gives more life to their years [8].

In the book of "Motricity, Fundamentals and Applications", authors have also successfully and currently received the field of Gerontomotricity, in which several chapters are devoted to the process of aging. These theories are attempting to explain the process of how various organs and systems are affected. Special attention is 
given to the deterioration of the elderly motor skills which occur frequently, like falling, immobilization and the need for technical assistance. It also emphasizes the importance of physical exercise for its numerous psychophysical benefits [12].

It is assumed that the functional impairment in elderly is due in part, to inactivity. Therefore, physical exercise becomes an important tool to improve the overall function in elderly and disabled [13] [14].

Autonomy in elderly is closely related to their quality of life. Exercise is the precursor and protector of such autonomy as well as the organic systems which conditioned it, besides preserving and improving mobility and joint stability and skeletal muscle power levers, and affects positively the quality of the bone, posture, motor behavior, self-image, etc., and definitely on the quality of life [8] [12].

Physical Activity in elderly must be practiced with the highest spiritual, physical and environmental possible respect, in order that people involved feel as part of a society which is conscious of its roles, functions and tasks. This effort is to enable our grandparents, parents and ourselves, in a not very distant future that belongs to human nature and, in particular, at this stage of life in the modern world that the vast majority will reach and experience [15].

Due to the above and since one of the main objectives in the care of elderly is preventing disability and promoting independence, the need for permanent residence elderly is clear as well as providing them with systematic geriatric assessment programs, in order to achieve a rational and integrated treatment and monitored plan, always promoting functionality of the older people. For this reason a program of physical activity is proposed to help elderly maintain their homeostatic levels, and improve their skills for everyday life. This program also halts the cumulative decline that inactivity generates. This is something that has been proposed clearly, well tested and been proven to be a therapeutic remedy to alleviate this deterioration.

The main and specific objective if this study is to determine if the implementation of a physical activation program in a three-month period reduces the risk of falling in elderly while staying confined to permanent residences. Therefore it will also contribute to providing evidence and data favoring those staying in nursing homes or permanent residences to improve their quality of life.

This study aims to provide information that will lead to reliable results in the study of inactivity and the benefits associated with the implementation of a systematic program of physical activity. The results, together with many others, serve as evidence of the urgent need to change the curriculum, not only in the field of training of teachers and health professionals, but any professional who can assist in this important and crucial area where most of us will soon be part of.

\section{Methodology}

\subsection{Subjects}

For this study 30 elderly from Chihuahua, Mexico were randomly selected. 15 subjects were assigned to the experimental group and 15 in the control group; 7 women and 8 men each group. Subjects aged between 60 - 84 years with a mean age of 78 years and a standard deviation of 6.5 ; the mean and standard deviation in the control group aged 77 and 7.4 years respectively, while in the experimental group the mean and the standard deviation is 80 and 0 years.

\subsection{Instrument}

Balance and gait assessment subscales were used taken from a Tinetti Scale: the two subscales are, implementation and direct observation, and both assess the ability of an individual to perform specific physical activity. Subscale I: Balance (9 items), assesses the different components of balance: sitting, getting up, sitting, in standing, etc. Subscale II: Gait (7 items), assesses the speed of walking, step length, base of support, the regularity of the steps and the temporal relationship between the phases of bipodal and unipodal support with 19 - 25 risk of falling, 5 times more risk of lower score than 19, and 26 - 28 score is considered normal.

\subsection{Procedure}

Collaboration agreements were made with the participating permanent residences for elderly as well as their signed consents of having a physical condition that would allow them to participate in this study. A Tinetti scale (pretest) was implemented according to the results of the pretest, subjects from the experimental and control 
groups were assigned. A physical activation program was applied to the experimental group, for 12 weeks from Monday to Friday and the control group stayed with their normal social activities. Every session had 10 minutes of warm-up exercise, 30 minutes of core part and 10 minutes for recovery and relaxation. The main purpose was to make all their bodies work in a soft and progressive way through joint mobility with simple and varied exercises which would help them know their own body and their range of movement. After the twelve weeks of applying this program, subjects had a Tinetti Scale post-test to analyze the data collected at this last stage.

\subsection{Data Analysis}

Frequency analysis and correlation were carried out among the studied categories (normal, with some risk of falling and 5 times the risk of falling). Data obtained, was used for comparative purposes from control and experimental groups. Analysis of variance was also used complemented by the application of Scheffe test to check the differences between the equilibrium points, gait and the total of Tinetti scale.

\section{Results}

In the control group, the evolution of the pattern of risk of falling from pre-test to post-test, according to the studied categories according to the application of Tinetti group scale was given as follows: 6 elderly with some risk of falling, two of them had a five-time greater risk of falling. While in the experimental group 1 of the 3 elderly with some risk of falling went to a normal situation in the post-test, and similarly the 11 elderly with five times more risk of falling, 5 of them went to a risk of falling, one to a normal situation and the other 5 maintained their falling pattern from the pre-test to the post-test (Table 1).

Overall in the control group during the pre-test, $40 \%$ of elderly have some risk of falling and the other $60 \%$ have five times the falling risk; in the post-test $27 \%$ of them have some risk of falling and remaining $73 \%$ has five times more the risk of falling. While in the experimental group, at the pre-test $7 \%$ of older people have a normal falling pattern; $20 \%$ some risk of falling, and the remaining $73 \%$ five times more the risk of falling; at the post-test $20 \%$ of the elderly show normal falling pattern, $47 \%$ some risk of falling, and the remaining $33 \%$ five times more the risk of falling (Figure 1).

Analysis of variance for the score of balance according to Tinetti scale determined a significant interaction of both variables, from pre-test to post-test an improvement is shown in the score of balance in the experimental group, a decrease in the score of control group and, a difference in favor in the post-test scores for the experimental group (Table 2 and Figure 2).

Analysis of variance for the gait score according to Tinetti scale determined as significant the interaction in both variables, showing a difference in favor of the experimental group in the post-test as well as an improvement in the gait score in this group from pretest to post-test (Table 3 and Figure 3).

Table 1. Patterns of falling risk in elderly during the pre-test and post-test phase, both groups.

\begin{tabular}{|c|c|c|c|c|}
\hline \multicolumn{5}{|c|}{ Control group } \\
\hline \multirow{2}{*}{ Pre-test } & \multicolumn{3}{|c|}{ Post-test } & \multirow{2}{*}{ Total } \\
\hline & Normal & Some risk of falling & Five times more risk of falling & \\
\hline Normal & 0 & 0 & 0 & 0 \\
\hline Some risk of falling & 0 & 4 & 2 & 6 \\
\hline Five times more of risk of falling & 0 & 0 & 9 & 9 \\
\hline Total & 0 & 4 & 11 & 15 \\
\hline \multicolumn{5}{|c|}{ Experimental group } \\
\hline \multirow{2}{*}{ Pre-test } & \multicolumn{3}{|c|}{ Post-test } & \multirow{2}{*}{ Total } \\
\hline & Normal & Some risk of falling & Five times more risk of falling & \\
\hline Normal & 1 & 0 & 0 & 1 \\
\hline Some risk of falling & 1 & 2 & 0 & 3 \\
\hline Five times more risk of falling & 1 & 5 & 5 & 11 \\
\hline Total & 3 & 7 & 5 & 15 \\
\hline
\end{tabular}

Note: $r_{\mathrm{s}}$ between pre-post test control group categories $=0.739 ; r_{\mathrm{s}}$ between pre-post test experimental group categories $=0.548$. 
Table 2. Analysis of variance for the average score on the Tinetti Balance Scale.

\begin{tabular}{ccccc}
\hline Source & SS & $d f$ & MS & 2.483 \\
Pre-Post & 12.150 & 1 & 12.150 & 109.350 \\
Pre-Post*Group & 109.350 & 1 & 4.893 \\
Error (Pre-Post) & 137.000 & 28 & 4.349 \\
\hline
\end{tabular}

${ }_{\mathrm{p}}^{\mathrm{p}}<0.05,{ }^{* *} \mathrm{p}<0.01,{ }^{* * *} \mathrm{p}<0.005$.

\begin{tabular}{ccccc}
\hline & & Group & \\
& \multicolumn{2}{c}{ Control } & & \multicolumn{2}{c}{ Experimental } \\
\hline Pre-test & & Post-test & Pre-test & Post-test \\
\hline $8.3_{\mathrm{a}}$ & & $6.5_{\mathrm{ab}}$ & $7.7_{\mathrm{c}}$ & $11.3_{\mathrm{bc}}$ \\
\hline
\end{tabular}

Note: Means sharing the same subscript differ, at least to a level of $p=0.05$ to each other.

Table 3. Analysis of variance for the gait average score on the Tinetti scale.

\begin{tabular}{ccccc}
\hline Source & SS & $d f$ & MS & F \\
Pre-Post & 35.267 & 1 & 35.267 & 38.400 \\
Pre-Post*Group & 38.400 & 1 & 3.903 \\
Error (Pre-Post) & 90.333 & 28 & 3.226 \\
\hline
\end{tabular}

${ }_{\mathrm{p}}^{*}<0.05,{ }^{* *} \mathrm{p}<0.01,{ }^{* * *} \mathrm{p}<0.001$.

\begin{tabular}{ccccc}
\hline & & & \\
& & & \\
& Control & & \multicolumn{2}{c}{ Experimental } \\
& & & \\
\hline Pre-test & Post-test & Pre-test & Post-test \\
\hline 7.1 & $7.0_{\mathrm{a}}$ & $6.5_{\mathrm{b}}$ & $9.6_{\mathrm{ab}}$ \\
\hline
\end{tabular}

Note: Means sharing the same subscript differ, at least to a level of $p=0.05$ to each other.

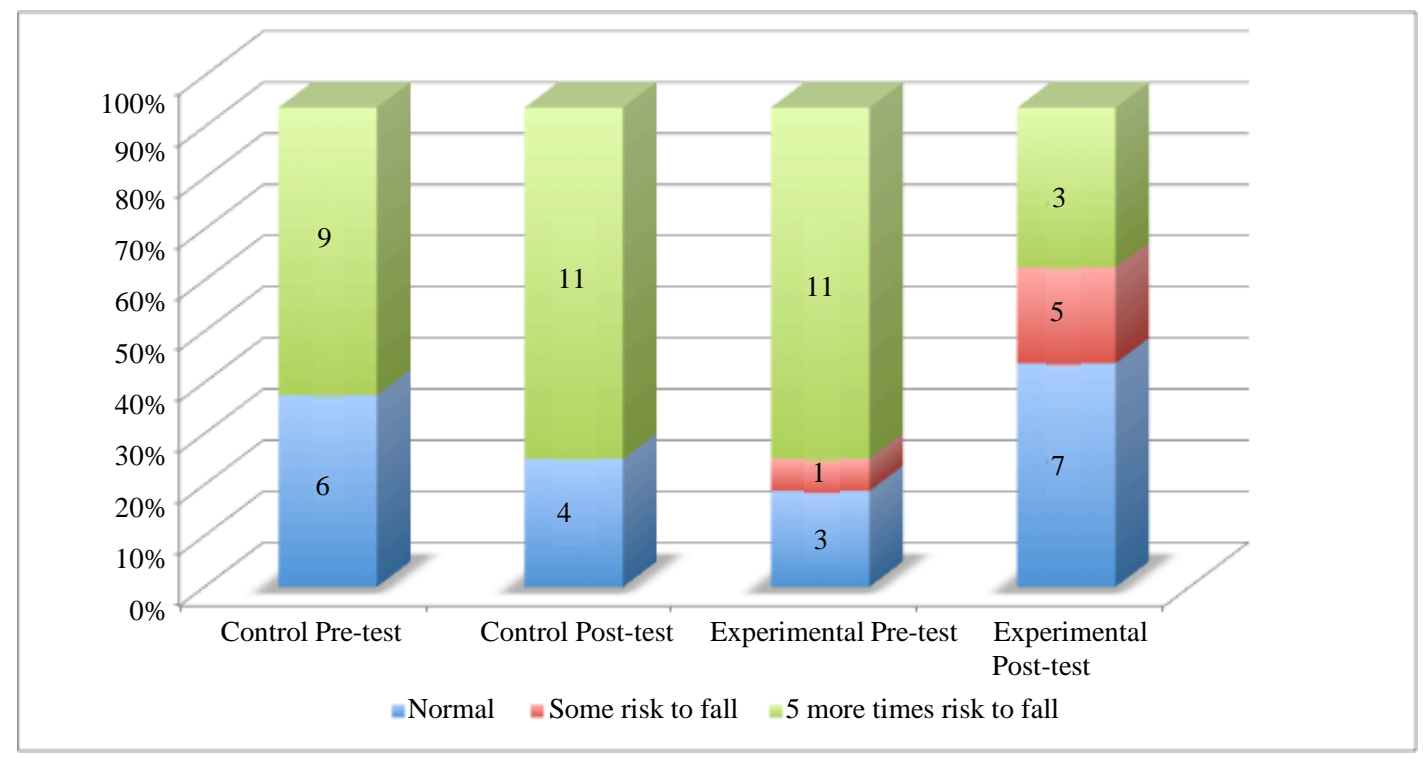

Figure 1. Patterns of falling risk in elderly during the pre-test and post-test phase, both groups. 


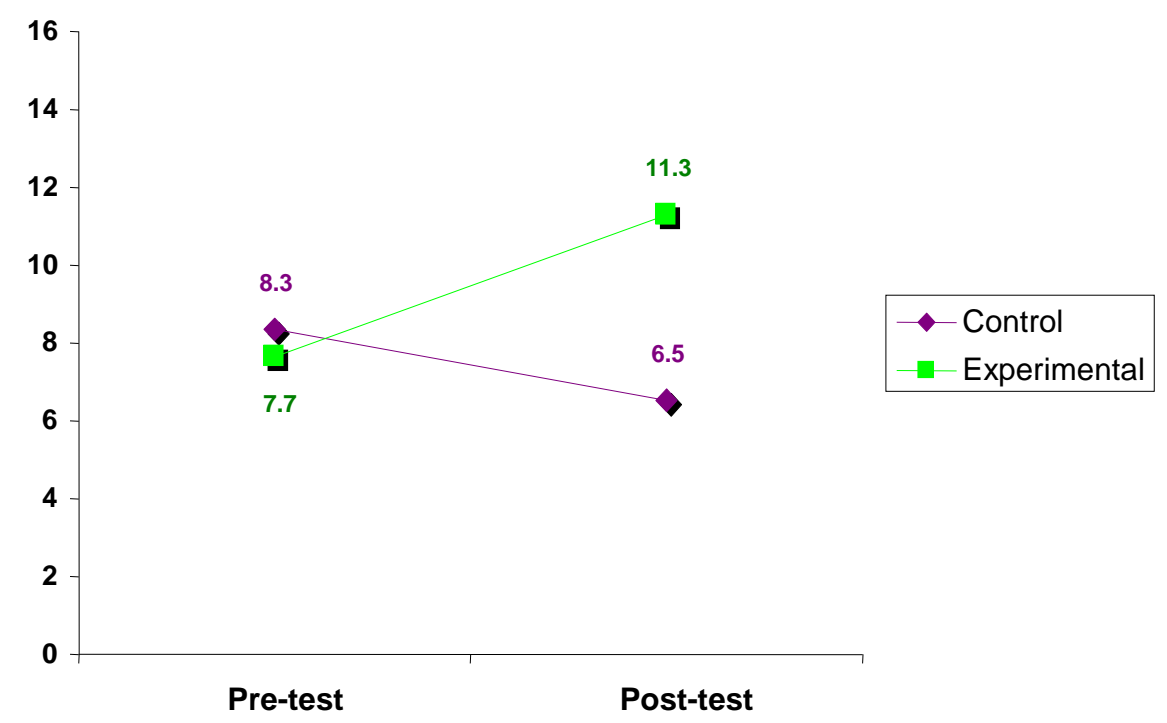

Figure 2. Mean score on the Tinetti Balance Scale pre-test - post-test control and experimental groups.

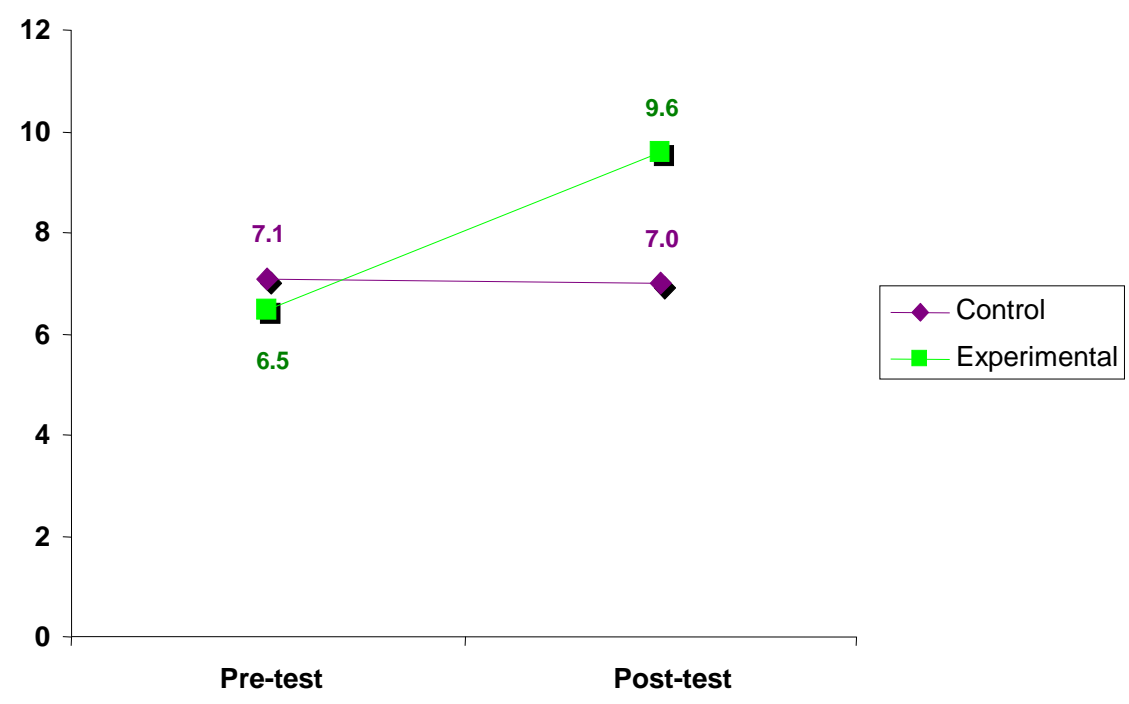

Figure 3. Mean score on the Tinetti scale of gait pre-test - post-test control and experimental groups.

\section{Discussions}

Regarding the developments in the pattern of falling risk from pre- to post-test, according to the categories studied by application of Tinetti scale, the results of frequency analyzes suggest greater stability in the pattern of falling in elderly from the experimental group compared to elderly in the control group. On the other hand, the analyzes of variance carried out showed a significant improvement in the balance of the experimental group, as well as a significant declination in the control group, in addition to the post-test there is a difference in favor of the score of the experimental group, being that in the pre-test groups were equivalent in this subject. Similarly, there is a meaningful improvement in the gait from pre-test to post-test in the experimental group, as well as a difference in favor of this group in the post-test, while in the pre-test, control and experimental groups were equivalent. Data obtained enhances the idea that, the Physical Activation Program has a significant improvement of balance and gait in Older Adults, reducing the risk of falling, as confirmed in a study by Ribeiro Teixeira, Broaching and Oliveira in Portugal [16], which revealed that a set of simple exercises to flex the ankle and foot improves strength and balance in older people. In another study Barrios, Borges and Cardoso [17] concluded 
that it is helpful to strengthen the legs and the body in general and increased safety from falls, frequent and dangerous phenomenon in the population; therefore, exercise contributes to the improvement of quality of life. Sherrington et al. (2008) [18] evaluated the reduction of falling in Physical Programs through 44 clinical trials, a total of 9603 men and women participated I this study. 65 percent were older than 75 years.

We must mention that the main limitation of the present study is the reduced sample size that includes only people who are living in nursing homes and do not apply to those elderly who live outside of these residences.

\section{Conclusion}

Data from these trials showed that programs were associated with 17 percent fewer falls. This conclusion supports again these findings and those of other authors in the same direction. In conclusion, results obtained comparing who participated in the implementation of a Physical Activation Program with those who did not, report accurately that Physical Activity performed by Older Adults in a dosed and systematical way improves the range and mobility of joints, which directly or indirectly affects their quality of life by reducing the risk of falling.

\section{Acknowledgements}

This study is part of a project funded by the Mexican Ministry of Education-Department of Higher EducationGeneral Directorate of the University Education [Secretaría de Educación Pública-Subsecretaría de Educación Superior—Dirección General de Educación Superior Universitaria de México] (OF-13-6894). Additionally, the second author is supported by a grant from the National Council of Science and Technology of Mexico (CONACYT).

\section{References}

[1] Jamison, D.T., Creese, A. and Prentice, T. (1999) The World Health Report 1999—Making a Difference. World Health Organization, Lyon.

[2] Salvarezza, L. (1998) Psicogeriatría, Teoría y Clínica. Paidos, México. [Salvarezza, L. (1998) Psychogeriatrics, Theory and Clinical. Paidos, México.]

[3] Instituto Nacional de Estadística Geografía e Informática (2005) Los adultos mayores en México. Perfil sociodemográfico al inicio del siglo XXI. Instituto Nacional de Estadística, Geografía e Informática, México. [National Institute of Statistics, Geography and Informatics (2005) Older Adults in Mexico. Sociodemographic Profile at the Beginning of XXI Century. National Institute of Statistics, Geography and Informatics, Mexico.]

[4] Montenegro, L., Salazar, C., De la Puente, C., Gómez, A. and Ramírez, E. (2009) Aplicación de la evaluación geriátrica integral en los problemas sociales de adultos mayores. Acta Médica Peruana, 26, 169-174. [Montenegro, L., Salazar, C., De la Puente, C., Gómez, A. and Ramírez, E. (2009) Implementation of Comprehensive Geriatric Assessment in the Social Problems of Older Adults. Acta Médica Peruana, 26, 169-174.]

[5] Varo, J.J., Martínez, J.A. and Martínez-González, M.Á. (2003) Beneficios de la actividad física y riesgos del sedentarismo. Medicina Clínica, 121, 665-672. [Varo, J.J., Martínez, J.A. and Martínez-González, M.Á. (2003) Benefits of Physical Activity and Risks of Physical Inactivity. Clinical Medicine, 121, 665-672.] http://dx.doi.org/10.1016/S0025-7753(03)74054-8

[6] Herranz, I., Lirio, J., Portal, E. and Arias, E. (2013) La actividad física como elemento de participación y calidad de vida en las personas mayores. Escritos de Psicología, 6, 13-19. [Herranz, I., Lirio, J., Portal, E. and Arias, E. (2013) Physical Activity as an Element of Participation and Quality of Life in Older People. Psychological Writings, 6, 13-19.] http://dx.doi.org/10.5231/psy.writ.2013.1906

[7] Serrano-del-Rosal, R., Biedma-Velázquez, L., Moscoso-Sánchez, D. and Martín-Rodríguez, M. (2013) Perceived Health, Physical Activity and Sport among the Elderly of Spain. Advances in Applied Sociology, 3, 151-156. http://dx.doi.org/10.4236/aasoci.2013.32020

[8] Aparicio, V.A., Carbonell-Baeza, A. and Delgado-Fernández, M. (2010) Beneficios de la actividad física en personas mayores. Revista Internacional de Medicina y Ciencias de la Actividad Física y el Deporte, 10, 556-576. [Aparicio, V.A., Carbonell-Baeza, A. and Delgado-Fernández, M. (2010) Benefits of Physical Activity in Older People. International Journal of Medicine and Science of Physical Activity and Sport, 10, 556-576.]

[9] Federación Internacional de Educación Física (2004) Manifiesto mundial de la educación física FIEP 2000. http://www.fiepmexico.com/manif.pdf [International Federation of Physical Education (2004) World Manifest of Physical Education IFPE 2000. http://www.fiepmexico.com/manif.pdf

[10] Jacoby, E., Bull, F. and Neiman, A. (2003) Cambios acelerados del estilo de vida obligan a fomentar la actividad física 
como prioridad en la Región de las Américas. Revista Panamericana de Salud Pública, 14, 223-225. [Jacoby, E., Bull, F. and Neiman, A. (2003) Rapid Changes in Lifestyle Make Increased Physical Activity a Priority in the Region of the Americas. American Journal of Public Health, 14, 223-225.] http://dx.doi.org/10.1590/S1020-49892003000900001

[11] Sañudo, J.I., Corrales-Sánchez, R. and Sañudo, B. (2013) Nivel de actividad física, calidad de vida y niveles de depresión en mujeres mayores con fibromialgia. Escritos de Psicología, 6, 53-60. [Sañudo, J.I., Corrales-Sánchez, R. and Sañudo, B. (2013) Level of Physical Activity, Quality of Life and Levels of Depression in Elderly Women with Fibromyalgia. Psychological Writings, 6, 53-60.] http://dx.doi.org/10.5231/psy.writ.2013.2806

[12] Collado, S., Pérez, C. and Carrillo, J.M., Eds. (2004) Motricidad. Fundamentos y aplicaciones. Dykinson, España. [Collado, S., Pérez, C. and Carrillo, J.M., Eds. (2004) Motricity. Fundamentals and Applications. Dykinson, España.]

[13] Liubicich, M.E., Magistro, D., Candela, F., Rabaglietti, E. and Ciairano, S. (2012) Physical Activity and Mobility Function in Elderly People Living in Residential Care Facilities. “Act on Aging”: A Pilot Study. Advances in Physical Education, 2, 54-60. http://dx.doi.org/10.4236/ape.2012.22010

[14] Manrique-Espinoza, B., Salinas-Rodríguez, A., Moreno-Tamayo, K. and Téllez-Rojo, M.M. (2011) Prevalencia de dependencia funcional y su asociación con caídas en una muestra de adultos mayores pobres en México. Salud pública de México, 53, 26-33. [Manrique-Espinoza, B., Salinas-Rodríguez, A., Moreno-Tamayo, K. and Téllez-Rojo, M.M. (2011) Prevalence of Functional Dependency and Its Association with Falls in a Sample of Elderly Poor in Mexico. Public Health of Mexico, 53, 26-33.]

[15] Lara, H. (2001) La actividad física en el adulto mayor. Revista educación física Chile, 255, 29-38. [Lara, H. (2001) Physical Activity in the Elderly. Physical Education Magazine Chile, 255, 29-38.]

[16] Ribeiro, F., Teixeira, F., Brochado, G. and Oliveira, J. (2009) Impact of Low Cost Strength Training of Dorsi and Plantar Flexors on Balance and Functional Mobility in Institutionalized Elderly People. Geriatrics and Gerontology International, 9, 75-80. http://dx.doi.org/10.1111/j.1447-0594.2008.00500.x

[17] Barrios, R., Borges, R. and Cardoso, L.D.C. (2003) Beneficios percibidos por adultos mayores incorporados al ejercicio. Revista Cubana de Medicina General Integral, 19. [Barrios, R., Borges, R. and Cardoso, L.D.C. (2003) Benefits Received by Seniors Incorporated Exercise. Cuban Journal of General Integral Medicine, 19.]

[18] Sherrington, C., Whitney, J. C., Lord, S.R., Herbert, R.D., Cumming, R.G. and Close, J.C.T. (2008) Effective Exercise for the Prevention of Falls: A Systematic Review and Meta-Analysis. Journal of the American Geriatrics Society, 56, 2234-2243. http://dx.doi.org/10.1111/j.1532-5415.2008.02014.x 